\title{
THE NITRIC OXIDE SYNTHASE COFACTOR TETRAHYDROBIOPTERIN REDUCES ALLOGRAFT ISCHEMIA-REPERFUSION INJURY AFTER LUNG TRANSPLANTATION
}

\author{
Ralph A. Schmid, MD \\ Sven Hillinger, $\mathrm{MD}^{\mathrm{a}}$ \\ Roland Walter, $\mathrm{MD}^{\mathrm{b}}$ \\ Andreas Zollinger, $\mathrm{MD}^{\mathrm{c}}$ \\ Uz Stammberger, MD \\ Rudolf Speich, MD \\ Andreas Schaffner, $\mathrm{MD}^{\mathrm{b}}$ \\ Walter Weder, MD ${ }^{\text {a }}$ \\ Gabriele Schoedon, $\mathrm{PhD}^{\mathrm{b}}$ \\ Sponsor: G Alexander Patterson, MD
}

Objective: Exogenous nitric oxide reduces ischemia-reperfusion injury after solid organ transplantation. Tetrahydrobiopterin, an essential cofactor for nitric oxide synthases, may restore impaired endotheliumdependent nitric oxide synthesis. We evaluated whether tetrahydrobiopterin administration to the recipient attenuates lung reperfusion injury after transplantation in swine. Methods: Unilateral left lung transplantation was performed in 15 weight-matched pigs $(24-31 \mathrm{~kg})$. Donor lungs were flushed with $1.5 \mathrm{~L}$ cold $\left(1^{\circ} \mathrm{C}\right)$ low-potassium-dextran solution and preserved for $\mathbf{2 0}$ hours. Group I animals served as controls. Group II and III animals were treated with a bolus of tetrahydrobiopterin (20 $\mathrm{mg} / \mathrm{kg}$ ). In addition, in group III a continuous infusion of tetrahydrobiopterin (10 mg/kg per hour over 5 hours) was given. One hour after reperfusion, the recipient right lung was occluded. Cyclic guanosine monophosphate levels were measured in the pulmonary venous and central venous blood. Extravascular lung water index, hemodynamic variables, lipid peroxidation, and neutrophil migration to the allograft were assessed. Results: In group III a significant reduction of extravascular lung water was noted in comparison with the controls $(P=.0047)$. Lipid peroxidation in lung allograft tissue was significantly reduced in group II $(P=.0021)$ and group III $(P=.0077)$ in comparison with group I. Pulmonary venous levels of cyclic guanosine monophosphate increased up to $23 \pm 1 \mathrm{pmol} / \mathrm{mL}$ at 5 hours in group II and up to $40 \pm 1 \mathrm{pmol} / \mathrm{mL}$ in group III (group I, $4.1 \pm 0.5 \mathrm{pmol} / \mathrm{mL}$ [I vs III]; $P<.001$ ), whereas central venous levels of cyclic guanosine monophosphate were unchanged in all groups. Conclusion: Tetrahydrobiopterin administration during lung allograft reperfusion may reduce posttransplantation lung edema and oxygen-derived free radical injury in the graft. This effect is mediated by local enhancement of the nitric oxide/cyclic guanosine monophosphate pathway. (J Thorac Cardiovasc Surg 1999;118: 726-32)
En ndothelial dysfunction is the central pathophysiologic mechanism of ischemia-reperfusion injury. Nitric oxide (NO) plays a key role in a number of basic endothelium-dependent mechanisms such as vasodilation, ${ }^{1}$ modulation of neutrophil adhesion, ${ }^{2}$ platelet aggregation, ${ }^{3}$ and maintenance of endothelial barrier properties. ${ }^{4}$ Recent studies demonstrate the protective

From the Department of Surgery, Division of Thoracic Surgery, ${ }^{\mathrm{a}}$ Department of Medicine, Medical Clinic B ${ }^{\mathrm{b}}$ and Department of Anesthesiology, ${ }^{\mathrm{c}}$ University Hospital, Zürich, Switzerland.

Supported by Swiss National Science Foundation grants 32-46004.95 (R. A. Schmid) and 32-42536.94 (G. Schoedon).

Read at the Seventy-ninth Annual Meeting of The American Association for Thoracic Surgery, New Orleans, La, April 18-21, 1999. effect of the administration of exogenous NO in the setting of ischemia-reperfusion after solid organ transplantation..$^{5-8}$

Tetrahydrobiopterin is an essential cofactor of all NO synthases (NOSs; Fig 1). Activation of NOSs under suboptimal concentrations of tetrahydrobiopterin leads to increased formation of oxygen radicals, ${ }^{9}$ which

Received for publication March 2, 1999; revisions requested May 18, 1999; revisions received June 18, 1999; accepted for publication June 21, 1999.

Address for reprints: Ralph A. Schmid, MD, Department of Surgery, University Hospital, Zürich, Rämistr 100, CH-8091 Zürich, Switzerland.

Copyright @ 1999 by Mosby, Inc.

$0022-5223 / 99 \$ 8.00+0 \quad \mathbf{1 2 / 6 / 1 0 1 2 0 4}$ 
mediate oxidative vascular injury. ${ }^{10}$ Furthermore, it has been shown that exogenous tetrahydrobiopterin restores impaired endothelium-derived NO synthesis in acute endothelial dysfunction. ${ }^{11}$

In a model of unilateral lung transplantation in swine, we investigated whether exogenous tetrahydrobiopterin enhances the $\mathrm{NO} /$ cyclic guanosine monophosphate (cGMP) pathway. In addition, we evaluated whether this treatment reduces posttransplantation lung ischemiareperfusion injury after prolonged preservation.

\section{Material and methods}

Animals and operative procedure. All animals received humane care in compliance with the European Convention on Animal Care. The protocol was approved by the local animals study committee. Fifteen weight-matched pairs of outbred pigs (24-31 kg) served as donors and recipients. Harvest and left lung transplantations were performed as previously reported. ${ }^{12}$ Preservation time was 20 hours at $1{ }^{\circ} \mathrm{C}$. One hour after reperfusion, the right contralateral lung was excluded from perfusion and ventilation.

Study groups. Animals were randomized into 3 groups. Group I $(n=5)$ served as controls, and no tetrahydrobiopterin was administered. In group II $(\mathrm{n}=5)$, the recipient animals were treated with tetrahydrobiopterin, $20 \mathrm{mg} / \mathrm{kg}$, given as a 30-minute bolus infusion started 15 minutes before reperfusion. In group III $(\mathrm{n}=5)$, in addition to the bolus, tetrahydrobiopterin was continuously infused at a dose of $10 \mathrm{mg} / \mathrm{kg}$ per hour during the entire 5-hour observation time.

Administration of tetrahydrobiopterin. Buffered solutions of (6R)-5,6,7,8-tetrahydro-L-biopterin-dihydrochloride (BH4; Dr B. Schircks Laboratories, Jona, Switzerland), 10 and $20 \mathrm{mg} / \mathrm{kg}$ body weight, respectively, were prepared directly before use as previously described. ${ }^{13}$ After dilution with $0.9 \% \mathrm{NaCl}$ to a total volume of $50 \mathrm{~mL}$, the solution was passed through a $0.2-\mu \mathrm{m}$ pyrogen-free filter (Schleicher \& Schuell, Feldbach, Switzerland). The light-protected solution was infused by an IVAC perfusor (IVAC Corporation, San Diego, Calif) at a constant flow of $99.9 \mathrm{~mL} / \mathrm{h}$ for bolus infusion and $50 \mathrm{~mL} / \mathrm{h}$ for continuous infusion, respectively.

Assessment. One hour after reperfusion of the transplanted lung, the right contralateral pulmonary arteries and the right main bronchus were ligated to assess allograft function only. During the assessment period, anesthesia was maintained with halothane (Fluothane) 1.5\%. Systemic arterial, pulmonary arterial, central venous, and left atrial pressure were recorded continuously. In addition, pulmonary venous and central venous blood was drawn for analysis of cGMP at the beginning of the assessment and hourly thereafter.

At the end of the assessment period, 5 hours after reperfusion, the animals were killed. Upper lobe allograft samples were taken for tissue myeloperoxidase and thiobarbituric acid reactive substance assay.

Extravascular lung water. Extravascular lung water (EVLW) as direct assessment of the reperfusion edema was

\section{NO pathway}

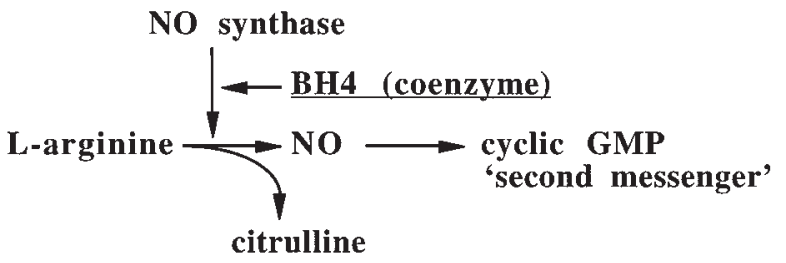

Fig 1. BH4 acts as essential coenzyme of NOSs to form NO and citrulline from L-arginine. NO stimulates the soluble guanylate cyclase to form cGMP, the second messenger of NO.

measured as previously described. ${ }^{12}$ Thoracic intravascular and extravascular fluid volumes are determined on the basis of the measurement of the mean transit times for thermal and dye indicators and of the decay time volumes calculated from the indicator-dilution curves as described previously. ${ }^{14}$ The lung water computer (System Cold Z-021; Pulsion, Munich, Germany) detects the mean transit time for the thermal indicator and for the dye indicator and calculates total thermal volume (ITTV), intrathoracic blood volume (ITBV), and extravascular thermal volume (ETV). ${ }^{15}$ The extravascular thermal volume (ETV) is calculated as follows: ETV = ITTV - ITBV. All measurements are made in triplicate. The mean value is used for analysis and expressed as EVLW index (EVLWI) in milliliters per kilogram of body weight.

Neutrophil migration. Donor and recipient lung samples were frozen immediately and stored at $-80^{\circ} \mathrm{C}$ until assay. Quantitative myeloperoxidase activity as the measurement for neutrophil migration into the allograft was determined by routine methods as previously described. ${ }^{16}$ Enzyme activity is expressed as change in optical density (at $460 \mathrm{~nm}$ ) per milligram of tissue protein per minute $(\Delta \mathrm{OD} / \mathrm{mg} / \mathrm{min})$.

Lipid peroxidation. Donor and recipient lung samples were frozen immediately and stored at $-80^{\circ} \mathrm{C}$ until assay. Thiobarbituric acid reactive substance levels were measured according to the method of Ohkawa and associates ${ }^{17}$ in $10 \%$ wet weight per volume homogenate. Myeloperoxidase levels were determined by reference to a standard curve of 1,1,3,3-tetramethoxypropane (Sigma Chemicals, Buchs, Switzerland), and the results were expressed as picomoles of malondialdehyde per gram of wet lung.

Measurement of plasma cGMP levels. Concentrations of cGMP were determined in pulmonary venous blood drawn from the left atrium and in peripheral venous blood drawn from the right ventricle of the recipient. Plasma was prepared and frozen at $-80^{\circ} \mathrm{C}$ until analysis by EIA (Biotrak cGMP assay; Amersham International plc, Amersham, United Kingdom) according to the manufacturer's instructions. The detection limit of the assay used was $46 \mathrm{fmol} /$ well.

Hemodynamic variables. Systemic arterial, pulmonary arterial, central venous, and left atrial pressure were recorded 


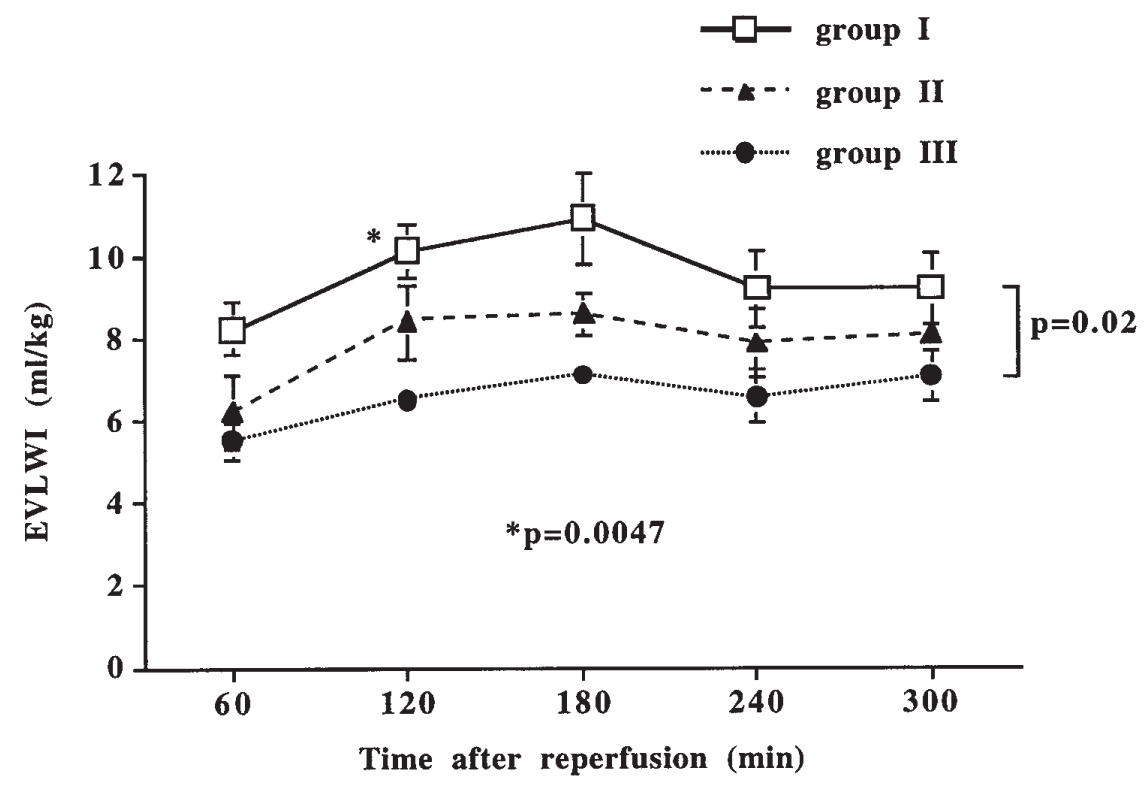

Fig 2. EVLW in the pulmonary allograft increased in the first 120 minutes after reperfusion followed by a slight decrease in the control group. The development of posttransplantation lung edema was significantly lower in the BH4-treated animals (mean \pm SEM).

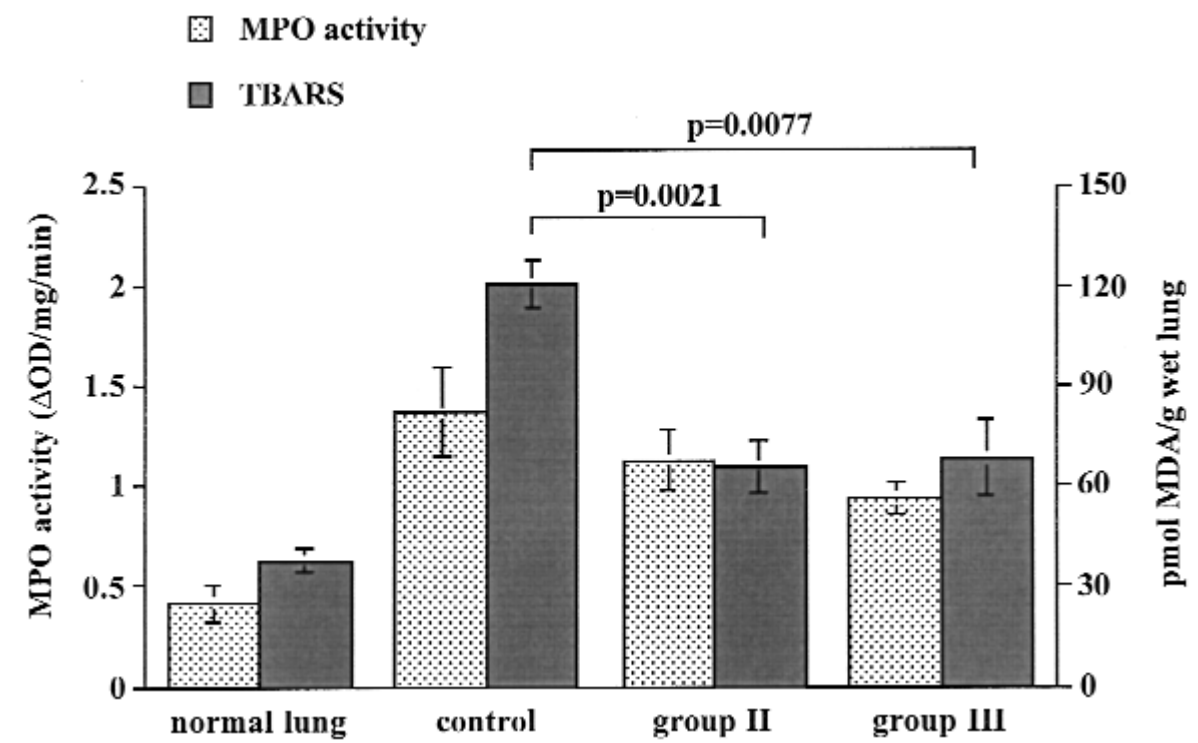

Fig 3. Leukocyte adhesion and lipid peroxidation. Polymorphonuclear migration measured as myeloperoxidase activity shows an increase after transplantation, but remarkably less in groups II and III . Thiobarbituric acid reactive substance (TBARS) levels in the allograft as the measurement for lipid peroxidation 5 hours after reperfusion were significantly reduced by treatment with tetrahydrobiopterin (mean $\pm \mathrm{SEM}$ ).

continuously with a hemodynamic monitor system (Hellige, Freiburg, Germany). Measurement of cardiac output is part of the lung water assessment (System Cold Z-021; Pulsion), the pulmonary vascular resistance was calculated in CGS units according to Poiseuille's law.

Statistical analysis. All values are given as the mean \pm standard error of the mean. Analysis for repeated measures was performed by analysis of variance (StatView 4.5; Abacus Concepts, Inc, Berkeley, Calif).

\section{Results}

Characteristics of experimental groups. No statistical differences between groups were noted in donor 


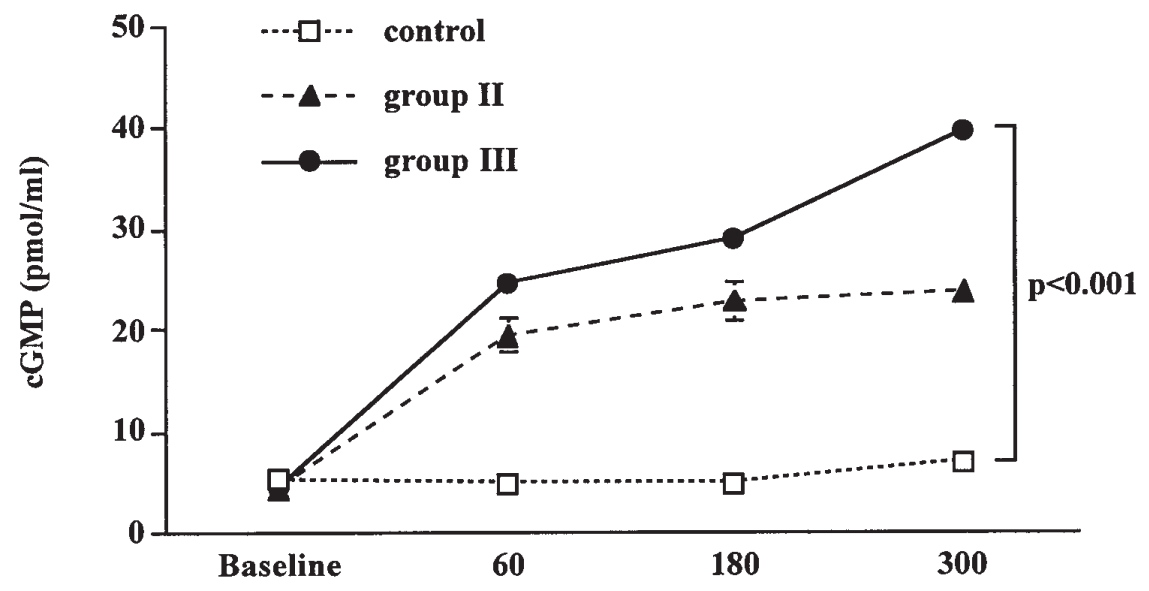

A

Time after reperfusion $(\mathrm{min})$

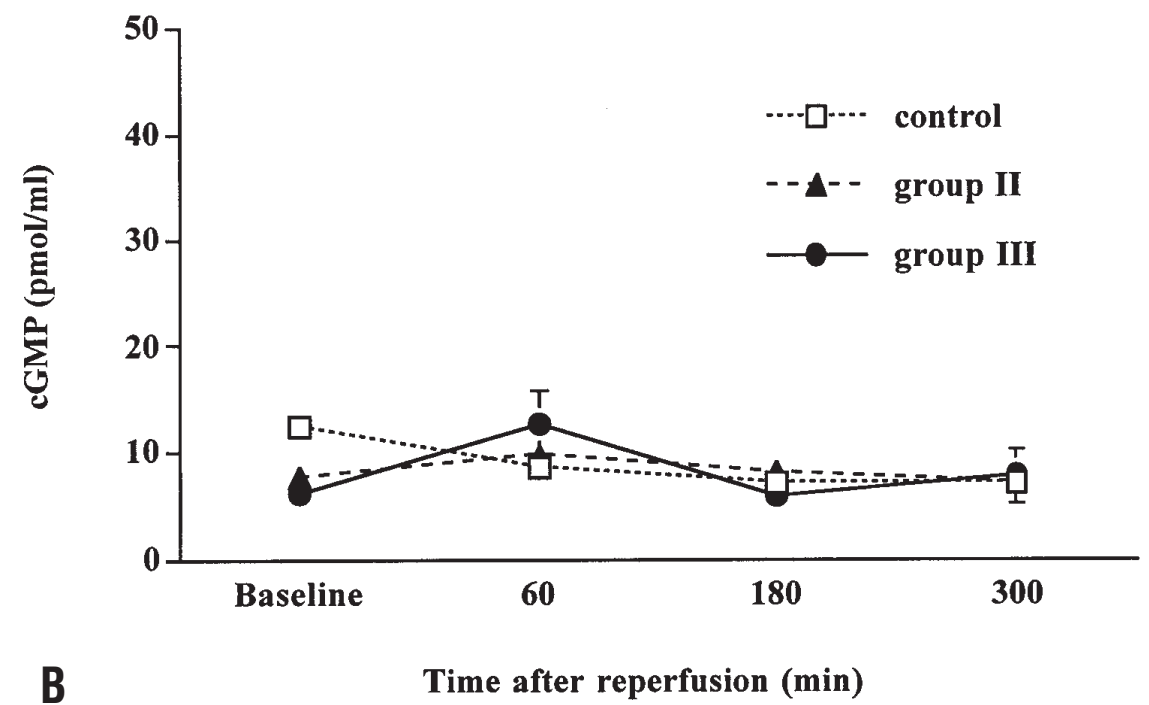

Fig 4. cGMP levels in pulmonary (A) and central venous blood (B) of lung allograft recipients (mean \pm SEM). The highest levels of cGMP were noted when the animals were treated with BH4 continuously.

weight $(27.1 \pm 2.8 \mathrm{~kg}$ in group I vs $29.6 \pm 3.7 \mathrm{~kg}$ in group II; $P=.57$, and $28.5 \pm 6.0$ in group III; $P=.65$ ), recipient weight $(27.6 \pm 5.1 \mathrm{~kg}$ in group I vs $27.6 \pm 2.1$ $\mathrm{kg}$ in group II; $P=.75$, and $26.8 \pm 5.2 \mathrm{~kg}$ in group III; $P=.81)$, total preservation time (1218 \pm 37 minutes in group I vs $1197 \pm 22$ minutes in group II; $P=.25$, and $1222 \pm 22$ minutes in group III; $P=.81$ ), and warm ischemic time ( $90 \pm 6$ minutes in group I vs $89 \pm 3$ minutes in group II; $P=.94$, and $88 \pm 5$ minutes in group III; $P=.65$ ) Values are given as the mean \pm standard error of the mean.

Reperfusion edema. As shown in Fig 2, EVLWI in the allograft was significantly lower in animals treated continuously with BH4 (overall difference group III vs group I; $P=.020$ ). This effect was most marked 2 hours after reperfusion $(10.1 \pm 0.6 \mathrm{~mL} / \mathrm{kg}$ in group I vs $7.0 \pm$ $0.5 \mathrm{~mL} / \mathrm{kg}$ in group III; $P=.0047)$. In group II, a tendency to reduced edema formation (EVLWI) in comparison to the controls was noted (overall difference group II vs group I; $P=.14$ ).

Neutrophil migration. Allograft myeloperoxidase activity tended to be lower after administration of BH4. Even though data were suggestive for an inhibition of neutrophil adhesion, the differences were not statistically significant $(1.37 \pm 0.22 \Delta \mathrm{OD} / \mathrm{mg} / \mathrm{min}$ in group I vs $1.13 \pm 0.15 \Delta \mathrm{OD} / \mathrm{mg} / \mathrm{min}$ in group II; $P=.39$, and $0.94 \pm 0.08 \Delta \mathrm{OD} / \mathrm{mg} / \mathrm{min}$ in group III; $P=.17$ ). Myeloperoxidase activity in normal unflushed lung tissue was $0.42 \pm 0.09 \Delta \mathrm{OD} / \mathrm{mg} / \mathrm{min}$ (Fig 3).

Lipid peroxidation. A significant change of malon- 


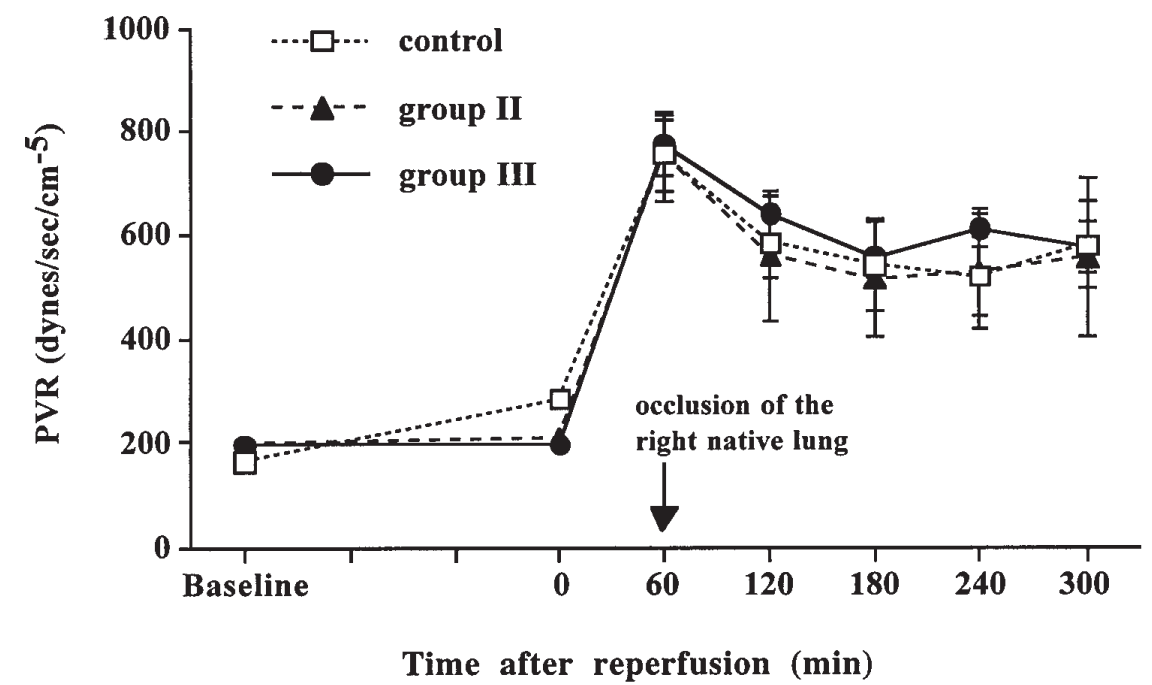

Fig 5. Pulmonary vascular resistance $(P V R)$. Pulmonary vascular resistance increased at the time of exclusion of the right native lung $(60 \mathrm{~min})$. BH4 treatment did not reduce this increase of pulmonary vascular resistance (mean \pm SEM).

dialdehyde concentration was shown in lung allograft tissue in group II, $65.7 \pm 7.9 \mathrm{pmol} / \mathrm{g}(P=.0021)$ and group III, $68.2 \pm 11.3 \mathrm{pmol} / \mathrm{g}(P=.0077)$ versus group I, $120.8 \pm 0.7 \mathrm{pmol} / \mathrm{g}$ (malondialdehyde concentration in normal lung tissue $41.3 \pm 4.2 \mathrm{pmol} / \mathrm{g}$; Fig 3 ).

Changes of cGMP levels. On BH4 administration, pulmonary venous cGMP levels increased during 5 hours up to $23 \pm 1 \mathrm{pmol} / \mathrm{mL}$ in group II and up to $40 \pm$ $1 \mathrm{pmol} / \mathrm{mL}$ in group III at the end of the assessment compared with untreated animals (group I $4.13 \pm 0.49$ $\mathrm{pmol} / \mathrm{mL} ; P<.001$ group I vs III; Fig 4, $A$ ). In all groups central venous cGMP was unchanged during the 5-hour observation period (at the end of the assessment in group I $7.1 \pm 0.1 \mathrm{pmol} / \mathrm{mL}$, in group II $7.2 \pm 0.4$ $\mathrm{pmol} / \mathrm{mL}$, and in group III $7.8 \pm 2.5 \mathrm{pmol} / \mathrm{mL} ;$ Fig $4, B$ ).

Hemodynamic parameters. No significant differences were noted in hemodynamic variables either during the 5-hour assessment period or at the end of the assessment: cardiac output $(3.1 \pm 0.4 \mathrm{~L} / \mathrm{min}$ in group I vs $4.2 \pm 0.4 \mathrm{~L} / \mathrm{min}$ in group II and $3.3 \pm 0.2 \mathrm{~L} / \mathrm{min}$ in group III; $P=.50)$, pulmonary arterial pressure $(32 \pm 3$ $\mathrm{mm} \mathrm{Hg}$ in group I vs $36 \pm 4 \mathrm{~mm} \mathrm{Hg}$ in group II and 32 $\pm 1 \mathrm{~mm} \mathrm{Hg}$ in group III; $P=.60$ ), and pulmonary vascular resistance $\left(580 \pm 85\right.$ dynes $\cdot \mathrm{sec}^{-1} \cdot \mathrm{cm}^{-5}$ in group I vs $557 \pm 152$ dynes $\cdot \mathrm{sec}^{-1} \cdot \mathrm{cm}^{-5}$ in group II and 575 \pm 48 dynes $\cdot \mathrm{sec}^{-1} \cdot \mathrm{cm}^{-5}$ in group III; $P=.69$; Fig 5 ).

\section{Discussion}

In the present study we demonstrate that $\mathrm{BH} 4$ treatment during lung allograft reperfusion enhances pul- monary venous cGMP levels and reduces post-transplant lung edema in a large animal model. This reduction, however, was statistically significant only when BH4 was administered continuously over the entire observation period. cGMP levels increased up to 10 times over control levels in the pulmonary venous blood of the graft. However, an improvement in pulmonary hemodynamics was not observed. This is in accordance with previous reports that noted that only infusion of high doses of BH4 in the brachial artery in human beings led to a marked local vasodilation. ${ }^{18}$ For substitution of NO-dependent vasodilation in patients with impaired endothelial function as the result of hypercholesteremia, however, relatively low doses of BH4 were sufficient. ${ }^{19}$ In addition, other effects were noted that indicate a reduction in reperfusion injury in our experiment. These include a reduction of oxygen/derived free radical-mediated injury and an at least suggestive reduction in neutrophil migration to the allograft. Even though we did not directly show that the cGMP levels were enhanced through the NO pathway, it is most probable that $\mathrm{BH} 4$ increases $\mathrm{NO}$ production by NOS because the known biologic role of $\mathrm{BH} 4$ is to act only as coenzyme of NOS and for the synthesis of neurotransmitters and amino acids.

Gas exchange, in this model, is not a parameter that can be used to assess the injury. If the ischemic time of the graft would be expanded to induce a reduction of gas exchange after reperfusion, the animal would die within 1 or 2 hours after reperfusion, and no repro- 
ducible data could be assessed. Moreover, the lung water computer used in this highly reproducible model allows for the assessment of hemodynamic variables and the dynamic changes of the lung edema.

Impaired endothelium-dependent NO synthesis after ischemia-reperfusion has been observed by a number of investigators, and different strategies have been proposed to substitute this endothelial dysfunction. In the lung for example, administration of L-arginine ${ }^{20}$ or NO donors $^{21}$ and NO inhalation ${ }^{7,22}$ have been evaluated in experimental and/or clinical settings. From the theoretic standpoint, L-arginine substitution does not increase NO synthesis, because intracellular L-arginine (0.8-2 $\mathrm{mmol} / \mathrm{L}$ ) concentration is much higher than the concentration at which the reaction velocity is half maximal $(2.9 \mathrm{mmol} / \mathrm{L}){ }^{23}$ Intravascular administration of NO donors affect the systemic circulation and NO inhalation, although having the advantage to be selective for the target organ is cumbersome for routine and prophylactic administration. Moreover, $\mathrm{BH} 4$ has some specific properties to qualify as the limiting step for NO synthesis in dysfunctional endothelium after ischemia and reperfusion. It increases the affinity of NOS to L-arginine ${ }^{24}$; it stabilizes NOSs, ${ }^{25}$ and it inhibits the negative feedback of NO on NOSs. ${ }^{26}$ In the absence of BH4, NOSs no longer produce NO but catalyze reactions leading to oxygen-derived free radical production. ${ }^{27}$ In addition, BH4 has a very low toxicity ${ }^{13}$ and can be administered even in high doses simply by the intravenous route.

Tiefenbacher and associates ${ }^{11}$ previously demonstrated in vitro, in isolated pig coronary arterioles, that exogenous administration of sepiapterin or the synthetic derivative 6-methyl-tetrahydropterin restores the response to endothelium-dependent vasodilators after ischemia and reperfusion and that limited availability of $\mathrm{BH} 4$ contributes to impaired endothelial vasodilation.

In conclusion, our study shows for the first time the effect of the NOS cofactor BH4 on post-transplantation ischemia-reperfusion injury in a large animal model. We could demonstrate that the administration of exogenous $\mathrm{BH} 4$ is a promising new therapeutic approach to substitute impaired NO/cGMP pathway after ischemia and reperfusion, resulting in reduced post-transplant edema in this complex and clinically relevant model of lung allograft reperfusion injury.

\section{REFERENCES}

1. Furchgott RF, Zawadzki JV. The obligatory role of endothelial cells in the relaxation of arterial smooth muscle by acetylcholine. Nature 1980;288:373-6.

2. Kubes P, Suzuki M, Granger DN. Nitric oxide: an endogenous modulator of leukocyte adhesion. Proc Natl Acad Sci U S A 1991;88:4651-5.

3. Radomski MW, Palmer RMJ, Moncada S. Endogenous nitric oxide inhibits human platelet adhesion to vascular endothelium. Lancet 1987;2:1057-8.

4. Kubes P, Granger DN. Nitric oxide modulates microvascular permeability. Am J Physiol 1992;262(Heart Circ Physiol 31):H6115 .

5. Pinsky DJ, Oz MC, Koga S, Taha Z, Broekman MJ, Marcus AJ, et al. Cardiac preservation is enhanced in a heterotopic rat transplant model by supplementing the nitric oxide pathway. J Clin Invest 1994;93:2291-7.

6. Naka Y, Chowdhury NC, Oz MC, Smith CR, Yano OJ, Michler $\mathrm{RE}$, et al. Nitroglycerin maintains graft vascular homeostasis and enhances preservation in an orthotopic rat lung transplant model. J Thorac Cardiovasc Surg 1995;109:206-11.

7. Okabayashi K, Triantafillou AN, Yamashita M, Aoe M, DeMeester SR, Cooper JD, et al. Inhaled nitric oxide improves lung allograft function after prolonged storage. J Thorac Cardiovasc Surg 1996;112:293-9.

8. Bacha EA, Sellak H, Murakami S, Mazmanian GM, Detruit H, Demontpreville V, et al. Inhaled nitric oxide attenuates reperfusion injury in non heartbeating donor lung transplantation. Transplantation 1997;63:1380-6.

9. Flavahan NASO. Atherosclerosis or lipoprotein-induced endothelial dysfunction: potential mechanisms underlying reduction in EDRF/nitric oxide activity. Circulation 1992;85:1927-38.

10. Cosentino F, Katusic ZSSO. Tetrahydrobiopterin and dysfunction of endothelial nitric oxide synthase in coronary arteries. Circulation 1995;91:139-44.

11. Tiefenbacher CP, Chilian WM, Mitchell M, DeFily DV. Restoration of endothelium-dependent vasodilation after reperfusion injury by tetrahydrobiopterin. Circulation 1996;94:1423-9.

12. Schmid RA, Zollinger A, Singer T, Hillinger S, Leon-Wyss JR, Schöb OM, et al. Effect of soluble complement receptor type 1 on reperfusion edema and neutrophil migration after lung allotransplantation in swine. J Thorac Cardiovasc Surg 1998;116:90-7.

13. Walter R, Blau N, Schaffner A, Schneemann M, Speich R, Stocker R, et al. Inhalation of the nitric oxide cofactor tetrahydrobiopterin in healthy volunteers. Am J Respir Crit Care Med 1997;156:2006-10.

14. Hachenberg T, Tenling A, Rothen HU, Nyström SO, Tyden H, Hedenstierna G. Thoracic intravascular and extravascular fluid volumes in cardiac surgical patients. Anesthesiology 1993;79: 976-84.

15. Wickerts CJ, Jakobsson J, Frostell C, Hedenstierna G. Measurement of extravascular lung water by thermal-dye dilution technique: mechanisms of cardiac output dependence. Intensive Care Med 1990;16:115-20.

16. Smith PK, Krohn RI, Hermanson GT, Mallia AK, Gartner FH, Provenzano MD, et al. Measurement of protein using bicinchoninic acid. Anal Biochem 1985;150:76-85.

17. Ohkawa H, Ohishi N, Yagi K. Assay for lipid peroxides in animal tissues by thiobarbituric acid reaction. Anal Biochem 1979;95: 351-8.

18. Schaffner A, Blau N, Schneemann M, Steurer J, Edgell C-JS, Schoedon G. Tetrahydrobiopterin as another EDRF in man. Biochem Biophys Res Comm 1994;205:516-23.

19. Stroes E, Kastelein J, Cosentino F, Erkelens W, Wever R, Koomans H, et al. Tetrahydrobiopterin restores endothelial function in hypercholesterolemia. J Clin Invest 1997;99:41-6. 
20. Shiraishi Y, Lee JR, Laks H, Waters PF, Meneshian A, Blitz A, et al. L-Arginine administration during reperfusion improves pulmonary function. Ann Thorac Surg 1996;62:1580-7.

21. Yamashita M, Schmid RA, Ando K, Cooper JD, Patterson GA. Nitroprusside ameliorates lung allograft reperfusion injury. Ann Thorac Surg 1996;62:791-7.

22. Date H, Triantafillou AN, Trulock EP, Pohl MS, Cooper JD, Patterson GA. Inhaled nitric oxide reduces human lung allograft dysfunction. J Thorac Cardiovasc Surg 1996;111:913-9.

23. Arnal JF, Münzel TH, Venema RC, James NL, Bai C, Mitch WE. Interactions between $\mathrm{L}$-arginine and L-glutamine change endothelial NO production. J Clin Invest 1995;95:2565-72.

24. Klatt P, Schmid M, Leopold E, Schmidt K, Werner ER, Mayer B. The pteridine binding site of brain nitric oxide synthase: tetrahydrobiopterin binding kinetics, specifity, and allosteric interaction with the substrate domain. J Biol Chem 1994;269:13861-6.

25. Kinoshita H, Tsutsui M, Milstien S, Katusic ZS. Tetrahydrobiopterin, nitric oxide and regulation of cerebral arterial tone. Prog Neurobiol 1997;52:295-302.

26. Hyun J, Komori Y, Chaudhuri G, Ignarro LJ, Fukuto JM. The protective effect of tetrahydrobiopterin on the nitric oxide-mediated inhibition of purified nitric oxide synthase. Biochem Biophys Res Comm 1995;206:380-6.

27. Scott-Burden T. Regulation of nitric oxide production by tetrahydrobiopterin. Circulation 1995;91:248-50.

\section{Discussion}

Dr Paolo Macchiarini (Hannover, Germany). Was the 20hour period chosen to induce a forced pulmonary edema or because you wanted to prolong or extend the ischemic time? The amount of pulmonary edema seems not that impressive to me. For instance, in the control group you had $10.1 \mathrm{~mL} / \mathrm{kg}$ and in the treated group 8.4 or $7 \mathrm{~mL} / \mathrm{kg}$. Therefore what is your clinical impression concerning really this difference and the treatment? I think that the weakest point of this study is that you did not clamp the right pulmonary artery, and therefore the respiratory support was dependent on both lungs.

Dr Schmid. Last question first: We did occlude the right pulmonary artery 1 hour after reperfusion.
Dr Macchiarini. Okay. Sorry. Thank you very much.

Dr Schmid. Maybe you are also working with the pig model. It is a very difficult model, because if you induce too much damage to the lung, the pigs die within a short time of right heart failure. This is our standard model: 20 hours from preservation time, prostaglandin $\mathrm{E}_{1}$ (alprostadil) and lowpotassium dextran solution to achieve reproducible results. Everything we can add to this high standard is for us quite impressive. We are now performing experiments with a preservation time of 30 hours using BH4 and cGMP. We think this supports the importance of the NO pathway during lung allograft reperfusion.

Dr Mark F. Ferguson (Chicago, Ill). In terms of group III, when you added the 8-Br-cGMP to the flush solution, why did you eliminate the prostaglandin $\mathrm{E}_{1}$ ?

Dr Schmid. We wanted to do a direct comparison between prostaglandin $\mathrm{E}_{1}$ and 8-Br-cGMP. We did not want to demonstrate that it is an additive effect, but we wanted to compare the standard with prostaglandin $\mathrm{E}_{1}$ to cGMP in the flush solution.

Dr Ferguson. Then do you think that there is an additive effect possible?

Dr Schmid. I guess so, because there are 2 different pathways. To evaluate an additive effect, we would need another group. I mean, you can do groups infinitely.

Dr Ferguson. Yes, that is right. The analog, 8-Br-cGMP, has the effects that are identical to cGMP?

Dr Schmid. Yes. A number of studies showed the mechanism in small animal models, the uptake in the endothelium and in the smooth muscle cells.

Dr Ferguson. Then tell me what the disadvantage would be of infusing that instead of using it in the flush.

Dr Schmid. We do not have the explanation yet. It is more effective if you give it in the flush solution. For intravenous administration to the recipient, we had to detect the dose first. If you give too much cGMP to the recipient, you have problems with systemic hypotension, which we can avoid if we give it in the flush solution.

\section{Timely}

The Journal of Thoracic and Cardiovascular Surgery delivers the information you need now. Articles usually appear within four months of acceptance. 